\title{
PEMBINAAN KELUARGA SAKINAH PERSPEKTIF DAKWAH FARDIYAH DI KELURAHAN BORONG KECAMATAN MANGGALA KOTA MAKASSAR
}

\author{
BESSE HADIJAH ABBAS \\ Pascasarjana Universitas Islam Negeri (UIN) Alauddin Makassar \\ Email : bessehadijahabbas@gmail.com
}

\begin{abstract}
:
This paper discusses the Sakinah family coaching with a perspective of Da'wah Fardhiyah in Borong Village of Manggala District of Macassart City. This paper investigates the issue by addressing it elaborates the Da'wah Fardhiyah methods for Sakinah family coaching. The factors are related to economy and aqida (faith). The aims of this issue is "How the method of Sakinah family coaching with a perspective of Da'wah Dardhiyah in Borong Village of Manggala District of Macassart City. In investigating the issue, this paper employ field research design by using personal communication approach and interpersonal da'wah approach. Furthermore, the samples for this research were selected using purposive sampling technique. Conclusion of Sakinah family is an ideal concept of a happy family. This research implies that Sakinah family can be achieved by maintaining strong will as well as good relationships with Allah, family members and show mutual love, undertanding, respect and helpfulness and good community members.
\end{abstract}

Keywords : Da'wah Fardhiyah, Communication, Sakinah family, Kota Makassar

\section{PENDAHULUAN}

Keluarga adalah jiwa dan tulang punggung masyarakat. Keluarga adalah institusi sosial terkecil yang didalamnya terdapat anggota keluarga yaitu, suami, istri dan anak (nuclear family) serta kedua orang tua suami-isteri dan kerabat lainnya (exended family). Keluarga dibentuk melalui pernikahan yang melalui pula proses pemilihan pasangan yang terbaik buat keluarga. Awal pemilihan pasangan yang baik akan menghasilkan keluarga yang baik pula Pernikahan dalam Islam melalui akad nikah yang sah yang mempunyai wali dan saksi kedua calon mempelai pengantin, diikat dengan akad/ perjanjian suci diatur berdasarkan syariat Allah sehingga terwujud keluarga sakinah mawaddah warahmah. Tujuan nikah adalah litaskunuu alaiha : merasa tentram dan menyempurnakan ibadah 
beserta mencari ridha Allah. Keluarga sakinah merupakan harapan setiap hamba Allah yang berkeluarga. Keluarga sakinah adalah keluarga yang hidup dengan ketenangan, damai, tentramm saling pengertian, saling menyanyangi dan terasa kepuasan hati yang nyaman. Pola hidup keluarga untuk pembinaan keluarga yang sakinah, mawaddah warahmah sebaiknya ditanamkan sedini mungkin. Misalnya akidah, ahklak dan nilai-nilai agama dalam etika dan budi pekerti yang sesuai ajaran agama utamanya agama Islam karena banyak keluarga muslim tapi belum merasakan keluarga yang sakinah mawaddah warahmah. Keluarga sakinah adalah keluarga yang merasakan ketenangan hidup dan damai dalam berkeluarga sedangkan mawaddah berarti penuh cinta yang mengharapkan kasih sayang, saling mencintai, saling menghargai, saling pengertian yang dibuktikan dengan sikap dan tingkah laku, dan warahmah juga berarti kasih sayang Allah swt. merupakan ketulusan hati, saling menyempurnakan dalam kegiatan yang sesuai syariat Islam sehingga suasana kedamaian, ketentraman, dan kebahagiaan hidup di dunia dan akhirat yang di ridhai Allah swt. Keluarga Sakinah merupakan penjabaran firman Allah swt QS al-rūm/30:21. Terjemahnya:

Dan di antara tanda-tanda (Kebesaran)-Nya ialah Dia menciptakan pasangan-pasangan untukmu dari jenismu sendiri, agar kamu cenderung dan merasa tenteram kepadanya, dan Dia menjadikan di antaramu rasa kasih dan saying. Sungguh, pada yang demikian itu benar-benar terdapat tanda-tanda (kebesaran Allah) bagi kaum yang berpikir.

Ayat tersebut menguraikan bahwa tujuan berumah tangga atau berkeluarga adalah untuk mewujudkan ketenteraman atau ketenangan jiwa dengan dasar mawaddah wa rahmah (saling mencintai dengann penuh kasih sayang beserta saling menghargai, saling melengkapi kebutuhan). Selain didasarkan pada alQur'an dan hadis, pembentukan keluarga sakinah, mawaddah wa rahmah dilandaskan pada landasan Yuridis formalnya yaitu (1) Undang-Undang Nomor 1 Tahun 1974 tentang menyatukan bathin antara seorang perempuan dan pria 
sebagai suami istri dengan tujuan membentuk keluarga (rumah tangga) yang bahagia berdasarkan Ketuhanan Yang Maha Esa. (2). Surat Edaran Departemen Agama RI No.59 B VII/01.01,1/3520/1999 Tentang Pembinaan Keluarga Sakinah. Tapi juga yang terpenting dalam keluarga yang sangat fundamental adalah pondasi yang dibangun dengan landasan agama yang kuat dengan akhlah yang mulia.

Artikel ini ingin melihat cara Pembinaan Keluarga Sakinah Perspektif Dakwah Fardiyah di Kelurahan Borong Kecamatan Manggala. Pokok dari artikel ini yaitu metode dakwah fardiyah dalam pembinaan keluarga sakinah di Kelurahan Borong Kecamatan Manggala.

\section{TINJAUAN TEORITIS}

\section{KELUARGA}

Masing-masing Anggota keluarga mempunyai Hak dan kewajiban untuk menjaga kelangsungan hidup anggota keluarga agar pemenuhan hak dan kewajiban dalam keluarga dapat menimbulkan suasana yang nyaman, maka diperlukan adanya pola hubungan antar anggota keluarga yang didasarkan pada kesetaraan nilai kemanusiaan. Pola hubungan tersebut akan mendorong munculnya pola komunikasi yang setara antar anggota keluarga. Komunikasi yang setara adalah komunikasi yang dilakukan dengan saling pengertian, penghargaan dan penghormatan antar anggota keluarga. Setiap individu menjalin hubungan dengan landasan takwah dan rahmah.

Orang banyak menyangka, tentang arti kedamaian dan kebahagiaan ini, tentu akan merasa kesulitan untuk mencari yang benar, karena sangkaan orang itu hanyalah bayangan belaka, bukan hak ikat daripada arti kedamaian dan kebahagiaan dihati. Orang menyangka bahwa orang yang damai dan bahagia hatinya adalah orang kaya adalah tidak benar, karena berapa banyak orang kaya 
yang tidak merasa kaya, ingin apa saja dapat terlaksana, ingin makan yang enak orang kaya yang tidak merasa kaya, sehingga rakus terhadap harta benda dan dalam hatinya terlintas hendak menguasai dan merebut kekayaan yang sebanyakbanyaknya. Pikiran kalut, memikirkan hasil ini dan itu, dan bahkan waktu untuk makan pun tidak ada karena banyaknya tamu dan pekerjaan. Seorang yang lumayan kaya yang pernah dikenal oleh peneliti, tetapi kurang damai hatinya dikarenakan kesehatannya terganggu, sehingga sulit tidur dan kehidupan sehariharinya selalu gelisah. Ini adalah suatu bukti bahwa kekayaan yang cukup belum tentu dapat menjamin ketentraman hati dan kedamaian hidup dalam keluarga. Kalau manusia hendak mengetahui siapa orang yang bahagia dan damai serta tentram hatinya itu hendaklah bertanya kepada Allah Swt., sebab hanya Allah yang mengetahui urusan roh, sebenarnya Allah telah memberikan petunjuk kepada manusia melalui firman-firman-Nya, di antaranya adalah :

1. Orang yang mentaati Allah dan Rasul-Nya pasti akan bahagia, sebagaimana firmannya QS al-Ahzab/33:7. Terjemahnya sebagai berikut: “ ...Dan barangsiapa mentaati Allah dan Rasul-Nya, Maka Sesungguhnya ia akan berbahagia yang besar. Sebenar-benarnya bahagia".

2. Dalam ayat lain disebutkan, bahwa manusia akan memperoleh ketentraman hati dengan jalan mengingat Allah, zikir kepada-Nya, sebagaimana firman-Nya. QS ar-Ra'ad/13:28. Terjemahnya:

"Orang-orang yang beriman dan hati mereka manjadi tenteram dengan mengin gat Allah. Ingatlah, Hanya dengan mengingati Allah-lah hati menjadi temteram.

Berdasarkan ayat tersebut di atas para ulama menjelaskan bahwa hati jadi tentram dan bahagia apabila menjalankan perintah dan menjauhi larangan-Nya sesuai ajaran Islam, dan selalu mengingat Allah.

${ }^{1}$ Kementerian Agama R.I. Al-Qur'an dan Terjemahnya, h. 290. 


\section{DAKWAH FARDHIYAH}

Agama berperan sebagai sumber utama untuk memecahkan seluruh masalah, sehingga perlu bagi suami istri memegang dan melaksanakan ajaran agama dengan sebaik-baiknya dalam arti mau dan mampu melaksanakan kehidupan beragama dalam kehidupan keluarga, baik dalam keadaan suka maupun duka.

Upaya kearah membentuk keluarga sakinah dapat dilaksanakan dengan cara gemar memperdalam ilmu agama dengan mendekatkan diri kepada Allah swt. dengan cara yaitu shalat pada waktunya, sering membaca buku-buku yang bernafaskan agama, sering mendengar ceramah agama, dan tiada hari tanpa baca al-Quran, bukan tiada hari tanpa HP dan lain-lain dan diaplikasikan didalam rumah tangga sebagai manusia yang beriman dan bertakwa membetuk keluarga sakinah. Dalam hal tersebut sangat dibutuhkan adalah dakwah karena dakwah adalah proses komunikasi yang berlandaskan syariat Islam utamanya dakwah fardhiyah yang sangat relevan dalam upaya menyadarkan pasangan suami istri dalam berumah tangga untuk merasakan keluarga sakinah. Dakwah fardhiyah terdiri dari tiga tahapan yaitu :

Pertama : Mafhum Da'wah yaitu usaha seorang dai mengenal dan menjaga hubungan baik dengan mad'u untuk dituntun kejalan Allah seperti disebutkan Firman Allah swt QS Fus\{s\{ilat/41:33 .Terjemahannya:

"Siapakah yang lebih baik perkataannya daripada orang yang menyeru kepada Allah, dan mengerjakan amal saleh, dan berkata : "sesungguhnya Aku termasuk orang-orang yang menyerah diri?."

Kedua : Mafhum Haraki (gerakan) yakni menjalin hubungan dengan masyarakat umum, kemudian memilih salah seorang dari mereka untuk membina hubungan lebih dekat, menampakkan kecintaan dan perhatian. 
Ketiga : Mafhun Tanzimi meliputi pengarahan berupa bimbingan seorang dai kepada mad'uw dalam rangka berdakwah kepada Allah swt. Untuk membantu memahami keadaan dirinya, memahami persoalan-persoalan dan hambatanhambatan yang dihadapinya, menunjukkan dengan cara halus tentang kemampuan dan kelebihan yang ia miliki.

Penegasan dalam hal ini dai membantu penerima dakwah untuk menentukan tempatnya dalam alam islami serta menunjukkan kepadanya kewajiban-kewajiban yang harus di penuhi posisi ini. Penting pula yaitu membangkitkan iman yang mengendap dalam jiwanya, memberikan bimbingan tentang yang dialaminya, dan penerima dakwah diarahkan untuk melakukan amalan yang sesuai serta tidak memberatkannya dilihat dari satu segi maupun segi yang lain ia dapat memperoleh kebahagiaan dunia akhirat.

Dakwah fardhiyah adalah proses ajakan atau seruan kepada jalan Allah yang dilakukan seseorang dai kepada perseorangan yang dilakukan secara langsung tatap muka atau langsung tetapi tidak tatap muka (bermedia) yang bertujuan memindahkan mad'uw pada keadaan yang lebih baik dan diridhai Allah swt.

Definisi dakwah fardhiyah ialah menyampaikan ajaran Islam yang ditujukan kepada seseorang secara berhadapan bisa terjadi dengan tidak dirancang terlebih dahulu, dengan definisi ini dakwah fardhiyah berarti interaksi seseorang sehingga respon mad'uw terhadap pesan dan dari dai dapat diketahui seketika baik secara positif maupun negatif.

Dakwah fardhiyah atau dakwahan antar-individu merupakan konseling Islam yaitu ajakan atau seruan ke jalan Allah yang dilakukan seorang dai (penyeruh) kepada orang lain secara perorangan dengan tujuan memindahkan mad'uw kepada keadaan yang lebih baik dan diridhai Allah.

Istilah dakwah fardiyah memang tidak begitu dikenal/ populer dibanding 
dengan lainnya seperti ceramah, tabligh akbar bahkan dakwah di media elektronik yang paling mereka pahami zaman sekarang, terbukti dengan diadakannya penelitian di lokasi meneliti yang dijadikan sampel peneliti, hanya satu orang saja yang paham dengan dakwah fardhiyah karena informan adalah alumni dakwah Usluhuddin IAIN Ujung Pandang.

Namun secara historis dakwah fardhiyah, telah dilakukan oleh para Rasul Allah, seperti Rasulullah saw dalam dakwah sembunyi-sembunyinya sangat kental dengan pendekatan dakwah fardhiyah, walau pun secara kuantitas hasil dakwah beliau selama kurang lebih tiga tahun hanya berhasil mengislamkan beberapa orang saja, namun secara kualitas.

Apa yang diberikan para alim ulama dalam layanan konseling boleh jadi tepat guna dibanding dengan apa yang dilakukan olaeh konselor profesional, tetapi karena tidak ada data tertulis, maka pengalaman berharga tersebut tidak dapat memberikan sumbangan yang memadai terhadap pengembangan disiplin ilmu konseling Islam / dakwah fardhiyah.

Di sinilah terdapat celah bagi perkembangan konseling Islam saat ini, agar nantinya bisa mengisinya dengan perjuangan untuk memajukan tradisi keilmuannya sehingga menjadi lebih terstruktur dan dapat teruji validitasnya.

Dakwah melalui konseling inilah yang perlu mendapatkan perhatian pada masa sekarang ini. Di tengah-tengah krisis multidimensi yang melanda masyarakat utamanya di Indonesia, sudah seharusnya peran konseling Islam atau dakwah fardhiyah lebih dioptimalkan agar ajaran Islam betul-betul dapat dijadikan sebagai pedoman dan petunjuk dalam kehidupan sehari-hari. strategi dakwah harus mempunyai metode atau cara yang ditempuh untuk mencapai hasil tujuan yang optimal dan memuaskan serta efektif dan efisien, tepat sasaran maka diperlukan metode dakwah. 
Kata metode diambil dari kata metodologi (bahasa yunani) yang secara etimologi berasal dari kata "metodos" yang berarti cara atau jalan dan logos artinya ilmu. Sedangkan secara semantik metode atau metodologi berarti ilmu pengetahuan yang mempelajari tentang cara-cara atau jalan yang ditempuh untuk mencapai satu tujuan dengan hasil yang efektif dan efesien.

Metode dakwah fardhiyah menurut Djamaluddin Ancok dalam buku konseling Islam dijelaskan, bahwa proses pemindahan atau perubahan sikap seseorang berlangsung melalui tiga proses dasar yang disebutnya tiga tahap perubahan sikap, yaitu attention (perhatian), comprehension (pemahaman), dan acceptance (penerimaan).

Orang tidak akan berubah sikap apabila ia tidak memperhatikan apa yang disampaikan oleh seorang dai, oleh karena itu, agar penyampaian dakwah dapat diterima harus ada usaha untuk menarik orang memperhatikan dakwah yang disampaikan., jika seseorang sudah mempunyai perhatian terhadap pesan dakwah, diharapkan akan paham terhadap pesan yang disampaikan.

Tingkat pemahaman ini tergantung pada teknik penyampaian pesan dakwah. Kemudian dalam hal ditolak atau diterimanya isi dakwah. Sebagai sikap hidup sangat ditentukan oleh pemahaman terhadap pesan dakwah dan juga sejauh mana pesan dakwah itu sesuai dengan kebutuhan dan nilai hidup mad'uw. Penerimaan pesan dakwah ini diharapkan orang akan menjalankan perintahperintah Islam yang disampaikan. Ketiga tahapan pijakan bagi konseling Islam menjadi teknik atau metode perubahan tingkah laku yang menjadi hakekat tujuan dari konseling Islam/ dakwah fardhiyah. Konseling Islam membutuhkan ilmu bantu psikologi dakwah dalam aplikasinya. Psikologi dakwah bertugas untuk mempelajari perilaku kejiwaan manusia yang terlibat dalam proses dakwah (dai dan made'uw), sehingga para dai mampu menguraikan bahasa dakwanya secara efektif. 
Dakwah fardhiyah lebih mudah dipahami dalam masyarakat kalau diucapkan dengan kata lain "konseling Islam" .

\section{METODE PENELITIAN}

Jenis penelitian ini adalah penelitian lapangan (field research) yaitu penulis melakukan penelitian langsung ke lokasi untuk mendapatkan dan mengumpulkan data.

Adapun pendekatan yang digunakan adalah pendekatan komunikasi antarpribadi dan pendekatan dakwah antarpribadi adalah proses penyampain pesan oleh komunikator kepada komunikan melalui media yang dan ciri/karakteristik dakwah fardhiyah dan komunikasi antarpribadi terdapat adanya kesamaan, bahwa interaksi yang terjadi adalah sifatnya pribadi, terjadi tatap muka dengan jumlah orang yang relatif sangat kecil, akan tetapi melihat perkembangan zaman sekarang yang memasuki abad informasi dan globalisasai, dakwah fardhiyah maupun komunikasi antarpribadi tidaklah harus terjadi tatap muka secara langsung (fisik) karena kecanggihan teknologi bisa saja komunikasi yang intens berlangsung di belahan dunia maya yang berbeda lewat vidio call, Hand Phone, artinya face to face tidak menjadi persyaratan utama dalam melaksanakan dakwah fardiyah.

Sumber data adalah peneliti untuk mendapatkan data yang akurat, akan tetapi sumber data terbagi dua yaitu data primer dan data sekunder. Data primer adalah sumber data yang langsung memberikan data kepada pengumpul data. Penelitian ini bersifat kualitatif, sebab yang dihasilkan data deskriptif, meliputi data yang menyangkut pembinaan keluarga sakinah perspektif dakwah fardiyah.

\section{PEMBAHASAN}

Pada kehidupan sehari-hari yang berkaitan dengan metode dakwah 
fardhiyah/ konseling Islam, maka ada beberapa metode yang akan dilakukan dari hasil penelitian yaitu :

\section{Tolong menolong di antara sesama.}

Menolong seseorang meerupakan bentuk kesadaran dan kepedulian terhadap nilai kemanusiaan. Memberi pertolongan merupakan investasi yang kelak akan dipetik keuntungannya, tidak hanya diakhirat, tetapi di duniapun akan dapat dirasakannya.

Tolong menolong adalah suatu tindakan atau perbuatan untuk membantu seseorang yang menciptakan wujud sifat yang baik. Tolong menolong akan timbul rasa solidaritas untuk saling membantu atau tolong menolong untuk antar sesama manusia. Tolong menolong antara sesama manusia adalah perbuatan yang mulia karena membantu orang, artinya orang beramal, tabanas akhirat.

\section{Silaturrahmi}

Silaturrahmi merupakan pembelajaran yang perlu dilestarikan eksistensinya sebagai orang beriman, karena bersilaturrahmi dalam berkomunikasi kepada siapa saja merupakan perwujudan ajaran Islam, silaturrahmi sebagai salah satu ruh pengembangan dirinya, yang maknanya jika kamu berbuat baik maka kebaikan itu untuk dirimu sendiri, dan jika kamu berbuat jahat maka kejahatanmu itu untuk dirimu sendiri, oleh sebab itu silaturrahmi mempunyai banyak manfaatnya sebagai berikut :

1. Silaturrahmi adalah menjalin persahabatan lebih akrab

2. Silaturrahmi adalah berarti memperlihatkan identitas keramahan

3. Silaturrahmi adalah berarti memperkuat makna kebersamaan

4. Silaturrahmi dapat memberikan satu alur informasi yang membuka peluang dan kesempatan usaha. 
5. Silaturrahmi berarti merealisasikan makna Islam, bahwa Islam adalah agama keselamatan, dan silaturrahmi adalah memperluas rezeki dan memperpanjang umur. Makna ini dilestarikan dari generasi ke generasi, maka lambat laun masyarakat menjadi berprilaku baik, yang menurut plato sebagaimana di kutip dari Muhmidayeli bahwa kehidupan yang baik, hanya terdapat pada masyarakat yang baik, yang tentunya kebaikan sangat nampak pada komunikasi yang bersangkutan terhadap orang lain.

Bersilaturrahmi dengan orang tua perlu karena orang tua kita yang melahirkan dan membesarkan sangat senang dan bahagianya melihat anaknya, karena kita sebaiknya dekat dengan orang tua, karena doa orang tua untuk anak yang diharapkan dapat dikabulkan oleh Allah swt. Dalam silaturrahmi, yang harus didahulukan yaitu silaturrahmi kepada kedua orang tua sebelum kepada yang lain.Banyak saudara-saudara kita yang sering main keteman-temannya, tetapi kepada orang tuanya sendiri jarang. Sesulit apa pun, harus tetap diusahakan untuk bersilaturrahmi kepada kedua orang tua, karena dengan dekat kepada kepada orang tua , insya Allah akan dimudahkan rezeki dan dipanjangkan umur.

Silaturrahim yang lebih intensif lebih bagus dalam hal yang positif akan tetap terjadi komunikasi yang baik pula.. Dengan silaturrahim kita bisa menjelaskan beberapa hal yang penting di lakukan, akan tetapi jika silaturrahim terputus maka terputuslah komunikasi, hal ini akan membuka lagi celah lebih besar bagi munculnya prasangka negative (su'uzhun) atau ghibah yang. Oleh sebah itu silaturrahim di butuhkan agar terjadi keterbukaan pendapat, visi dan misi sehingga terjalin saling pengertian, saling menghargai sesama umat Islam.

\section{Nasehat}


Nasehat yang baik (mauidzah hasanah) adalah berdakwah dengan memberikan nasehat nasehat atau menyampaikan ajaran Islam dengan rasa kasih sayang, sehingga nasihat dan ajaran Islam yang disampaikan itu dapat berkenan di hati, menyentuh perasaan, lurus dipikiran, menghindari sikap kasar dan tidak mencari atau menyebut kesalahan audiens sehingga pihak objek dakwah dengan rela hati dan atas kesadarannya dapat mengikuti ajaran yang disampaikan oleh pihak subjek dakwah bukan propaganda yang memaksakan kehendak kepada orang lain. ${ }^{2}$

Dakwah fardhiyah atau konseling Islam bertujuan untuk menyelesaikan masalah yang ada pada suami istri sebagai nasehat, tetapi walaupun sudah dinasehati tapi tidak memperhatikan dan memahami keadaan keluarga dan dirinya menuju keluarga sakinah Sebagaimana firman Allah dalam QS ar$\operatorname{Rad} / 13: 11$.

Terjemahnya:

"Sesungguhnya Allah tidak merobah keadaan sesuatu kaum sehingga mereka merobah keadaan yang ada pada diri mereka sendiri. dan apabila Allah menghendaki keburukan terhadap sesuatu kaum, Maka tak ada yang dapat menolaknya; dan sekali-kali tak ada pelindung bagi mereka selain Dia.

Ayat tersebut di atas menjelaskan dengan tegas Allah tidak akan mengubah nasib suatu kaum sehingga mereka berusaha keras untuk merubah nasibnya sendiri, sehingga perlu menasehati jangan berpangku tangan, bermasa bodoh. Berusaha menambah pendapatan keluarganya terutama akan nasehat masalah akidah karena dia tidak memperhatikan shalatnya. Adapun nasehat yang diberikan dari dari kunjungan ke rumah yaitu :

1. Manusia dapat pengetahuan baru

${ }^{2}$ Moh. Ali Aziz, Ilmu Dakwah (Surabaya : Kencana, 2008), h. 218. 
2. Belajar dari pengalaman orang yang telah mengalaminya baik yang sukses maupun dikala gagal mencapai tujuannya.

3. Dapat mengetahui peluang peluang untuk berusaha. Dapat menambah ilmu tentang agama, agar sadar jadi kepala rumah tangga sebagai Imam dalam keluarga dan rasa tanggung jawab ada.

\section{Bimbingan}

Bimbingan adalah suatu metode belajar dalam mengajar mendidik secara khusus yang teliti dan serius pada tingkat pemahaman yang semaksimal mungkin sesuai kemampuan seseorang. Membimbing anak mengaji adalah akhlak mulia, berbeda bimbingan belajar mengambar yang punya bakat yang mudah di ajarkan yang tidak terlalu menguras pikiran.

Perjalanan hidup berumah tangga tidak selamanya mulus, cepat atau lambat jalan yang mulus itu akan di terpa yang berkerikil terkena guyuran hujan dan terpaan matahari, masalah akan terlihat satu demi satu, bisa saja muncul dari luar atau dari dalam, apapun masalahnya, kedua pasangan harus tetap menutupi dan menampakkan kebahagiaan, karena hanya dengan kemesraan, kita tahu rasa lezatnya, nikmatnya berumah tangga.

\section{SIMPULAN}

Keluarga sakinah mempunyai peran dan fungsi untuk membentuk manusia-manusia bertakwa dan membentuk masyarakat yang damai dan sejahtera Konsep keluarga sakinah di dalamnya penuh dengan Mahabbah, mawaddah dan warahmah yang di gambarkan oleh Islam adalah harus berpedoman pada al-quran dan hadis dan Ijtihad para ulama, kemudian memiliki komitmen dan tujuan yang sama mencapai kebahagiaan dunia akhirat yang di ridhai oleh Allah swt. keluarga sakinah, memerlukan persiapan ilmu, mampu mengamalkannya, dilakukan dengan ikhlas, selalu menjaga hati dan membutuhkan komitmen untuk bersinergi 
dalam peran masing-masing. Serta mampu menjadikan rumah sebagai baiti jannati yang mampu memberikan ketenangan dan ketentraman bagi semua anggota keluarganya, menjadikan rumah sebagai pusat ilmu, pusat nasehat, dan pusat berbagai kemuliaan.

Keluarga sakinah mampu memenuhi kebutuhan lahir dan bathin,saling tenggang rasa, saling pengertian dan melaksanakan hak dan kewajiban masingmasing dan mampu menghadapi dan menyelesaikan masalah yang muncul dalam keluarga sehingga pada akhirnya tercipta suasana kehidupan yang harmonis dalam lingkungan keluarga, masyarakat, bangsan dan negara, dan melahirkan generasi atau keturunan yang soleh dan solehah. Orang tua sebagai pendidik menyediakan ruang dan waktu untuk diri dan anak-anaknya belajar dan mengembangkan potensi dalam diri dengan menekankan dalam aspek, keimanan, pendidikan, akidah, dan akhlaknya apalagi khusus pada anak-anaknya mulai sebelum lahir hingga dewasa sehingga terwujud keluarga yang sakinah mawaddah wa rahmah

Pelaksanaan dakwah dalam keluarga merupakan satu yang sangat penting, karena dakwah mampu memberikan pengetahuan yang luas beserta tentang agama dalam keluarga yaitu keimanan dan etika adab berbicara beserta akhlak yang mulia. Dai melaksanakan dakwah banyak cara yang dapat ditempuh sesuai dengan visi dan misinya. Salah satu metode dakwah adalah penyampaian dakwah secara personal atau yang biasa dsebut dengan dakwah fardiyah. Metode ini sangat diperlukan dengan proses komunikasi antarpribadi, di mana saangat diperlukan keahlian keterampilan berbicara, selain keterampilan mendengarkan, keterampilan berbicara juga sangat menunjang keberhasilan sebuah komunikasi bagi dai untuk melihat mad'uwnya secara personal.

\section{DAFTAR PUSTAKA}

Abdurrahman, Arroisi. Laju Zaman Menentang Dakwah. Cet. II; Bandung: Remaja Rosda Karya Ofseet 1993.

Ahmad, A.Kadir, Dasar - dasar Metodologi Penelitian Kualitatif. Makassar: Indobis Media Centre, 2003. 
Al-Danawi, Saifuddin Aman, Nikmatnya Berumah Tangga. Cet. Pustaka Al Mawardi 2006.

Al-Majlisi, Syeikh Kabir, Sendi-sendi Pokok Rumah-Tangga Keluarga Rasulullah. Cet.I Gema Risalah Press Bandung, 1988.

Amin, Muliaty, Arifuddin .,St.Nasriah,., Ilmu Dakwah. Dicetak CV. Berkah Utami, Alauddin Press 2009.

Amirin, Psikologi Dakwah. Cet. I; Jakarta: Bulan Bintang, 1977.

Arifuddin, Keluarga dalam Pembentukan Akhlak Islamiah. Yogyakarta: Ombak. 2015.

Azis, Ali Moh., Ilmu Dakwah. Cet. VI; Kencana, Jakarta 2004.

Cresswell, J.W., Design Qualitative and Quantitative Approaches Thousand Oaks. .California: Sage Publications; 1998.

Departemen Pendidikan Nasional, Kamus Bahasa Indonesia. Balai Pustaka, 2005.

Faisal, Sanafiah, Metodologi Peneletian Sosial. Cet; 1 Jakarta; Erlangga, 2001.

Gay, L.R., and Geoffrey E.Mills, Peter Airasian, Educaation Research: Competencies for Anaalysis and Application. USA: Pearson Education Inc, $10^{\text {th }}$ ed.2012.

Gunawan, Imam, Metode Penelitian Kualitatif Teori dan Praktik, Jakarta: PT Bumi Aksara, 2016.

Ilaihi Wahyu, Komunikasi Dakwah. Cet. II PT. Remaja Rosdakarya, Bandung.

Isyas Ismail dan Prio Hotman, Filsafat Dakwah. Jakarta, Prenada Media Group, 2011.

Jasad, usmans, Semua Bisa Bahagia Terapi Hidup Sehari-hari.( Cet.I Noura Books Pt Mizan Publika, Jakarta Selatan,, 2018

Kabir Syeikh, Al-Majilsi, Sendi-sendi Pokok Rumah Tangga Keluarga Rasulullah. Cet.1: Gemah Risalah ; Press Bandung, 1988.

Lestari, Sri, Psikologi Keluarga Penanaman Nilai dan Penanganan Konflik dalam Keluarga. Cet III, Kencana Prenadamedia Group, 2014.

Lee,Thayer, Communication and Communication System: Organization Manage ment, and Interpersonal Relations. Homewood Illinois Richard D. Irwin.Inc.1968.

Lofland, Jhon dan Lyn H, Analyzing Sosial Setting: A Guide to Qualitative Observation and Analysis. Belmont Cal: Wardworth Publishing Company, 1984. 
Mahmud, Ali Abdul Halim, Dakwah Fardiyah Metode membentuk Pribadi Muslim. Cet.1:Gema Insani Press, 1995.

M. Echols, John dan Hassan Shadily, Kamus Inggris Indonesia. Cet.XX1X : PT. Gramedia Indonesia; Jakarta 2010.

Mansyur Amin,Dakwah Islam dan Pesan Moral. Cet 1, Yogyakarta al-Amin Press, 1997.

M.Zain,H.A.Majdah.,Menuju Research University dan Kampus Qu'ran. Cet;1;Makassar Sulawesi Selatan, 2015.

Nasuttion, S., Metode Research. Jakarta: Bumi Aksara, 2007.

Nuh, Sayid Muhammad, Dakwah Fardiyah Pendekatan-Peendekatan Personal dalam Dakwah. Cet.II; Era Intermedia Surakarta: 2000.

Provinsi Sulawesi Selatan, Departemen Agama, Proyek Peningkatan Pelayanan Kehidupan Beragama Sulawesi Selatan Bidang Urusan Agama Islam, Membina Keluarga Sakinah 2004.

Qurasih Shihab,M., Membumikan Al-Quran. Fungsi dan Peran Wahyu Dalam Kehidupan Masyarakat. Bandung: Mizan 1994.

, Keluarga Sakinah. Dalam Jurnal Bimas Salam, Vol.4 No1. 2011.

Rafi'uddin, at all, Prinsip dan Strategi Dakwah.Cet.1;Bandung;CV Pustaka Setia 1997.

RI, Departemen Agama, Al-Quran dan Terjemahnya. Jakarta: PT. Dharma Karsa Utama 2015.

Ridwan, Muhammad Saleh, Keluarga Sakinah Maa waddah Warahmah. Cet. UIN Press Makassar.

Said bin Ali al-Qathani, Dakwah Islam Dakwah Bijak. Cet.1,Jakarta Gema Insaani Press.1994.

Seha, Sampo H. Paradikma Dakwah Menata Ulang Penerapan Dakwah. Cet.I, UIN Press Makassar.

Slamet Muhaemin, Abda.,Prinsip-prinsip Metodologi Dakwah. Cet.I ; Surabaya; Al-Ikhlas, 1994.

Sugiyono, Metode Penelitian Pendidikan: Pendekatan Kuantitatif, Kualitatif, Dan R 7 D. Bandung : Alfabeta, 2013. 
Sulaiman, Al-Umar,Nashir, Ada Surga di Rumahku. Cet.II,Insan Kamil Solo, Jawa Tengah,Maret, 2013.

Syekh Muhammad, Abduh, Risalah Tauhid, Terj. Firdaus AN. Risalah Tauhid Jakarta : Bulan Bintang,UIM Algazali University. 2016.

Winangsih Syam, Nina, Sugiana. Dadang, Perencanaan Pesan dan Media Cet.I.; Pusat Penerbitan Universitas Terbuka Jakarta. 2001. 